\title{
Sterile endophthalmitis after intravitreal injection of bevacizumab obtained from a single batch.
}

\section{$\operatorname{AUTHOR}(S)$ :}

Yamashiro, Kenji; Tsujikawa, Akitaka; Miyamoto, Kazuaki; Oh, Hideasu; Otani, Atsushi; Tamuara, Hiroshi; Ooto, Sotaro; Sasahara, Manabu; Iwama, Daisuke; Yoshimura, Nagahisa

\section{CITATION:}

Yamashiro, Kenji ...[et al]. Sterile endophthalmitis after intravitreal injection of bevacizumab obtained from a single batch.. Retina 2010, 30(3): 485-490

\section{ISSUE DATE:}

2010-03

URL:

http://hdl.handle.net/2433/139464

\section{RIGHT:}

(C) 2010 Lippincott Williams \& Wilkins; This is not the published version. Please cite only the published version.; この論文は出版社版でありませ ん。引用の際には出版社版をご確認ご利用ください。 
Full Title: Sterile Endophthalmitis after Intravitreal Injection of Bevacizumab Obtained from a Single Batch

Abbreviated Title: Sterile Endophthalmitis after IVB

Authors: KENJI YAMASHIRO, MD, PhD, AKITAKA TSUJIKAWA, MD, PhD, KAZUAKI MIYAMOTO, MD, PhD, HIDEASU OH, MD, PhD, ATSUSHI OTANI, MD, PhD, HIROSHI TAMUARA, MD, PhD, SOTARO OOTO MD, PhD, MANABU SASAHARA, MD, DAISUKE IWAMA, MD, NAGAHISA YOSHIMURA, MD, PhD

From the Department of Ophthalmology and Visual Sciences, Kyoto University Graduate School of Medicine, Kyoto, Japan.

Correspondence: Kenji Yamashiro, MD, PhD, Department of Ophthalmology and Visual Sciences, Kyoto University Graduate School of Medicine, 54 Kawahara, Shogoin, Sakyo, Kyoto 606-8507, Japan. Phone: +81-75-751-3253; fax: +81-75-752-0933. e-mail: yamashro@kuhp.kyoto-u.ac.jp The authors have no financial conflict of interest.

Disclosure of funding: This study was supported in part by grants-in-aid for scientific research (Nos. 19390442 and 19592015) from the Japan Society for the Promotion of Science, Tokyo, Japan, and the Japan National Society for the Prevention of Blindness, Tokyo, Japan. The authors indicate no financial conflict of interest. 
Key words: age-related macular degeneration, bevacizumab, branch retinal vein occlusion, endophthalmitis.

Summary Statement: We report 14 consecutive cases of sterile endophthalmitis after intravitreal injection of bevacizumab obtained from a single batch. Ocular pain, hyperemia, cellular infiltration, and vitreous opacity appeared a few days after the injection. Most eyes regained initial visual acuity after treatment, which included pars plana vitrectomy in some cases. 
Purpose: To report 14 consecutive cases of endophthalmitis after intravitreal injection of bevacizumab obtained from a single batch.

Methods: One vial of bevacizumab $(100 \mathrm{mg} / 4 \mathrm{ml})$ was divided into 20 sterile injections and kept at $4^{\circ} \mathrm{C}$ before use. Bevacizumab $(1.25 \mathrm{mg} / 0.05 \mathrm{ml})$ was injected intravitreally into 19 eyes of 15 patients to treat macular edema or choroidal neovascularization. All treatments were performed within 1 week of the bevacizumab, which was from a single batch, being aliquotted into the 20 doses.

Results: Of the 19 eyes, 14 showed moderate to severe ocular inflammation shortly after injection. Cultures of aqueous humor and vitreous from 5 eyes were negative for bacteria and fungi. Eyes with moderate inflammation received topical or systemic antibiotics and steroid treatment. Five eyes with severe inflammation underwent pars plana vitrectomy because of dense vitreous opacity. Visual acuity returned to pre-endophthalmitis levels in 12 eyes but had declined in 2 eyes at one month after the injection.

Conclusions: Intravitreal injection of bevacizumab can cause sterile endophthalmitis. Most inflammation occurred within a few days after the intravitreous injection of the bevacizumab, but treatment with antibiotics, steroids, and/or vitrectomy was effective, and the prognosis was good in most cases. 
Bevacizumab (Avastin, Roche, Basel, Switzerland) is a recombinant humanized monoclonal antibody against vascular endothelial growth factor that was developed originally to treat metastatic carcinoma of the colon and rectum. ${ }^{1}$ Because it was designed to be used systemically, Michels and colleagues used off-label bevacizumab intravenous infusions to treat neovascular age-related macular degeneration (AMD). ${ }^{2}$ After the efficacy of intravenous bevacizumab on AMD was proved, it was administered intravitreally, ${ }^{3,4}$ and injection of intravitreous bevacizumab (IVB) began to be used widely for treatment of various ocular diseases, including branch retinal vein occlusion (BRVO), 5,6 polypoidal choroidal vasculopathy $(\mathrm{PCV}),{ }^{7,8}$ retinal angiomatous proliferation (RAP), ${ }^{9,10}$ myopic choroidal neovascularization (CNV), ${ }^{11,12}$ CNV secondary to angioid streaks (AS), ${ }^{13,14}$ proliferative diabetic retinopathy, ${ }^{15,16}$ and neovascular glaucoma. $^{17,18}$

IVB can cause complications, including traumatic cataract, retinal detachment, and endophthalmitis, with the reported incidence of endophthalmitis ranging from $0.014 \%$ to $0.082 \% .^{19-24}$ Although several cases of sterile endophthalmitis have been reported, most of these cases have been sporadic and in most instances the inflammation subsided with no treatment or with topical treatment. ${ }^{4,25-27}$

In late December 2008, Genentech issued a letter informing ophthalmologists about 36 cases of intraocular adverse reactions following the off-label use of intravitreal bevacizumab. Most cases that have been reported 
occurred in patients who received intravitreal bevacizumab from a single batch.

However, the precise ocular symptoms, reaction to the treatment, and visual prognosis have not been reported.

In the present study, we describe 14 consecutive cases of sterile endophthalmitis after injection of IVB, some of which required pars plana vitrectomy. Each of these 14 eyes was treated with bevacizumab that originated from a single batch. 


\section{Patients and Methods}

The current study was approved by the Institutional Review Board at Kyoto University Graduate School of Medicine, and all investigations adhered to the tenets of the Declaration of Helsinki.

Commercially available bevacizumab $(100 \mathrm{mg} / \underline{4 \mathrm{ml}})$ was aliquotted into smaller doses $(\underline{5 \mathrm{mg} / 0.2 \mathrm{ml} \times 20})$ under sterile conditions by the pharmacy unit and maintained at $4 \stackrel{\circ}{\circ}$ for less than a week prior to use. Intravitreal bevacizumab $(1.25 \mathrm{mg} / 0.05 \mathrm{ml})$ was injected into nineteen eyes of fifteen patients: three eyes of three patients with BRVO, six eyes of five patients with AMD, two eyes of two patients with PCV, three eyes of two patients with RAP, three eyes of two patients with myopic CNV, and two eyes of one patient with CNV secondary to AS (Table 1). Each of these patients received IVB within one week of the bevacizumab being aliquotted from a single vial. Triamcinolone acetonide was intravitreously injected with the bevacizumab in two eyes, and photodynamic therapy was performed three days after the bevacizumab injection in three eyes. The average age of the 15 patients was $77.3 \pm 9.1$

years. Previous treatment with intravitreal bevacizumab had been performed in 12 eyes $(63.2 \%)$.

All patients used antibiotic eye drops (gatifloxacin) for a week before the IVB treatment. After topical anesthesia, the eye and the lids were disinfected. Bevacizumab was injected into the vitreous cavity at a distance of 
3.5-4.0 mm posterior to the corneal limbus with a 30-gauge needle. The injection site was compressed for one minute with a cotton swab to avoid reflux when the needle was withdrawn. Patients were directed to use the antibiotic eye drops (gatifloxacin) for an additional week after the injection of IVB.

All values are presented as mean \pm SD. The data were analyzed by Fisher's exact test. Measurement values of three groups were compared using analysis of variance with post hoc comparisons tested by the Scheffe procedure. $P$ values of less than 0.05 were considered to be statistically significant 


\section{Results}

Ocular inflammation occurred in 14 eyes of 11 patients a few days after IVB injection (Tables 1 and 2), while the other 5 eyes did not show any inflammatory sign after receiving the IVB. The vitreous opacity became so dense that the optic disc could be observed only barely in 5 eyes, which were classified as the "severe inflammation" group; the other 11 eyes with inflammation were classified as the "moderate inflammation" group. The 5 eyes without inflammation were classified as the "no inflammation" group.

In eyes with severe ocular inflammation, the patients complained of eye pain and moderate conjunctival hyperemia. Slitlamp examination revealed moderate to severe cellular infiltration in the anterior chamber and vitreous cavity; three eyes showed hypopyon. The vitreous opacity became extensively dense in spite of intravenous antibiotics (imipenem), and visual acuity declined to count fingers in two eyes, to 2.0 in logMAR in two eyes, and to 1.5 in logMAR in one eye. These five eyes with severe ocular inflammation underwent pars plana vitrectomy (PPV) with instillation of intravitreal antibiotics (vancomycin and ceftazidime) on the third day; a sample of aqueous humor and vitreous was collected for culture. These cultures were all negative for Gram-positive bacteria, Gram-negative bacteria, and fungi.

Eyes with moderate ocular inflammation were treated with topical antibiotics (gatifloxacin and cefmenoxime) with or without a topical steroid 
(betamethasone). In the two eyes with moderate vitreous opacity, systemic

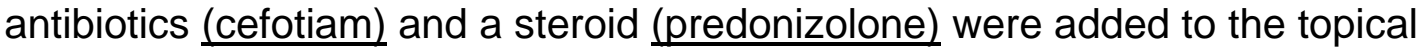
treatment. The inflammatory reaction in the anterior segment subsided within one week and the vitreous opacity subsided within a month. Some of the eyes thought to have no inflammation were not examined for several days after having been seen on the day after IVB injection, so ocular inflammation may have been present for a few days, without consultation, in these eyes.

Each patient was followed-up for at least one month after IVB treatment. Visual acuity was unchanged from pretreatment levels in 17 eyes but declined in 2 (Figure); it was restored to the level before IVB injection in the "no inflammation" group and in the "moderate inflammation" group, but declined in two eyes in the "severe inflammation" group.

A previous intravitreal injection of bevacizumab had been given $0.80 \pm$ 0.84 times in the "no inflammation" group, $1.67 \pm 1.87$ times in the "moderate inflammation" group, and $2.20 \pm 2.17$ times in the "severe inflammation" group, so there was no significant difference in the frequency of a prior IVB injection ( $P$ $=0.46)$. Furthermore, there was no significant difference when the experience was compared among the three groups: two eyes without prior IVB and three eyes with prior IVB in the "no inflammation" group, four eyes without prior IVB and five eyes with prior IVB in the "moderate inflammation" group, and one eye without prior IVB and four eyes with prior IVB in the "severe inflammation" group. No inflammatory reaction was detected after any of these previous IVB 
injections.

Cataract surgery had been performed in one eye (20\%) in the "no inflammation" group, in three eyes (33\%) in the"moderate inflammation" group, and in four eyes (80\%) in the "severe inflammation" group, so there was no statistically significant difference in the lens status between the groups.

\section{Case 15}

This representative patient was an 82-year-old female with CNV secondary to high myopia; axial length was $32.0 \mathrm{~mm}$ in each eye. Her left eye had been treated previously three times with IVB. Since new CNV had developed in each eye, she had received intravitreal injections of $1.25 \mathrm{mg}$ bevacizumab in each eye, with an interval of 3 months. On the day following the second injection, she noted moderate ocular pain and conjunctival hyperemia in both eyes. Slitlamp examination revealed moderate cellular infiltrate in the anterior chamber and vitreous cavity, but no hypopyon. The aqueous humor was collected for culture and intravenous antibiotic (imipenem) and topical antibiotic (gatifloxacin and cefmenoxime) treatment was begun. On the third day after IVB, however, the vitreous opacity became so dense that the optic disc could barely be seen and visual acuity declined to count fingers. Urgent vitrectomy was performed with instillation of intravitreal antibiotics (vancomycin and ceftazidime); a sample of the aqueous humor and vitreous was collected for culture. Both of these 
cultures and the previously performed test on aqueous humor were negative for Gram-positive bacteria, Gram-negative bacteria, and fungi. The inflammation subsided within a week and visual acuity returned to 1.0 in logMAR in both eyes by one month after the operation. 


\section{Discussion}

The present study consists of 14 consecutive cases of endophthalmitis after intravitreal injection of bevacizumab that had been derived from a single batch. Because cultures of the aqueous humor and vitreous from five eyes with severe endophthalmitis were negative for bacteria and fungi, these eyes were believed to have a sterile endophthalmitis. Except for two eyes with severe endophthalmitis, the visual acuity returned to that measured initially. Although it is possible that inflammatory signs were not seen in those patients who did not return to the hospital for several days after examination on the day immediately after that of IVB injection, for analysis we classified the 19 cases in the present study into one of three groups: "no inflammation", "moderate inflammation", and "severe inflammation".

Intravitreal injection of triamcinolone acetonide can also cause sterile endophthalmitis. In the present study, however, triamcinolone acetonide could not have been the sole cause of the ocular inflammation because severe inflammation occurred in eyes that did not receive triamcinolone acetonide.

Taban et al. have shown a possible association with prior history of uveitis in sterile endophthalmitis after intravitreal triamcinolone acetonide (IVTA) ${ }^{28}$ However, no patient in the present study had a history of uveitis. Pseudophakia is also a risk factor for sterile endophthalmitis after IVTA, ${ }^{29}$ but, because the lens status was not different among the three groups (i.e., "no inflammation", 
"moderate inflammation", and "severe inflammation"), this was not a risk factor for ocular inflammation after injection of IVB in the present study.

Because bevacizumab is a full-length humanized IgG antibody, repeated injection might increase the risk of sterile endophthalmitis. However, in the study described herein, prior IVB did not affect the severity of ocular inflammation. Recently, Stepien et al. reported a clustering of sterile endophthalmitis after IVTA that occurred during the same period at three clinical centers that were located very near to each other. ${ }^{30}$ They suggested that endotoxin in the same lot, or in lots produced close together, might have caused these cases of sterile endophthalmitis. Wickremasinghe et al. have reported 19 cases of acute severe intraocular inflammation after IVB treatment at six different clinical practices. They also suggested the possibility that trace endotoxin contamination of the bevacizumab, contamination whose level was not sufficient to cause any sign when administered systemically, ${ }^{31}$ might have resulted in the intraocular inflammation. Our 14 cases of sterile endophthalmitis caused by a single batch of bevacizumab seem to support these hypotheses. The 14 cases in the present study might represent sterile endotoxin-induced uveitis, considering that five eyes were negative for culture and the inflammatory reaction in the remaining nine eyes subsided with steroid treatment.

In summary, we have reported 14 consecutive cases of sterile endophthalmitis after intravitreal injection of bevacizumab that was derived from 
a single batch. Most of these cases developed inflammatory signs a few days after IVB injection. All eyes, save two, had a return of visual acuity after treatment, including PPV, to that measured initially. 


\section{References}

1. Yang JC, Haworth L, Sherry RM, et al. A randomized trial of bevacizumab, an anti-vascular endothelial growth factor antibody, for metastatic renal cancer. N Engl J Med 2003;349:427-434.

2. Michels S, Rosenfeld PJ, Puliafito CA, et al. Systemic bevacizumab (Avastin) therapy for neovascular age-related macular degeneration twelve-week results of an uncontrolled open-label clinical study. Ophthalmology 2005;112:1035-1047.

3. Rosenfeld PJ, Moshfeghi AA, Puliafito CA. Optical coherence tomography findings after an intravitreal injection of bevacizumab (avastin) for neovascular age-related macular degeneration. Ophthalmic Surg Lasers Imaging 2005;36:331-335.

4. Spaide RF, Laud K, Fine HF, et al. Intravitreal bevacizumab treatment of choroidal neovascularization secondary to age-related macular degeneration. Retina 2006;26:383-390.

5. Rabena MD, Pieramici DJ, Castellarin AA, et al. Intravitreal bevacizumab (Avastin) in the treatment of macular edema secondary to branch retinal vein occlusion. Retina 2007;27:419-425.

6. Wu L, Arevalo JF, Roca JA, et al. Comparison of two doses of intravitreal bevacizumab (Avastin) for treatment of macular edema secondary to branch retinal vein occlusion: results from the Pan-American Collaborative Retina Study Group at 6 months of follow-up. Retina 2008;28:212-219. 
7. Ghajarnia M, Kurup S, Eller A. The therapeutic effects of intravitreal bevacizumab in a patient with recalcitrant idiopathic polypoidal choroidal vasculopathy. Semin Ophthalmol 2007;22:127-131.

8. Song JH, Byeon SH, Lee SC, et al. Short-term safety and efficacy of a single intravitreal bevacizumab injection for the management of polypoidal choroidal vasculopathy. Ophthalmologica 2008;223:85-92.

9. Costagliola C, Romano MR, dell'Omo R, et al. Intravitreal bevacizumab for the treatment of retinal angiomatous proliferation. Am $\mathrm{J}$ Ophthalmol 2007;144:449-451.

10. Ghazi NG, Knape RM, Kirk TQ, et al. Intravitreal bevacizumab (avastin) treatment of retinal angiomatous proliferation. Retina 2008;28:689-695.

11. Chan WM, Lai TY, Liu DT, Lam DS. Intravitreal bevacizumab (Avastin) for myopic choroidal neovascularization: six-month results of a prospective pilot study. Ophthalmology 2007;114:2190-2196.

12. Ikuno $\mathrm{Y}$, Sayanagi $\mathrm{K}$, Soga $\mathrm{K}$, et al. Intravitreal bevacizumab for choroidal neovascularization attributable to pathological myopia: one-year results. Am J Ophthalmol 2009;147:94-100.

13. Bhatnagar P, Freund KB, Spaide RF, et al. Intravitreal bevacizumab for the management of choroidal neovascularization in pseudoxanthoma elasticum. Retina 2007;27:897-902.

14. Rinaldi M, Dell'Omo R, Romano MR, et al. Intravitreal bevacizumab for choroidal neovascularization secondary to angioid streaks. Arch Ophthalmol 
2007;125:1422-1423.

15. Mason JO 3rd, Nixon PA, White MF. Intravitreal injection of bevacizumab (Avastin) as adjunctive treatment of proliferative diabetic retinopathy. Am J Ophthalmol 2006;142:685-688.

16. Avery RL, Pearlman J, Pieramici DJ, et al. Intravitreal bevacizumab (Avastin) in the treatment of proliferative diabetic retinopathy. Ophthalmology 2006;113:1695-1705.

17. Kubota T, Aoki R, Harada Y, et al. Intravitreal injection of bevacizumab to treat neovascular glaucoma. Jpn J Ophthalmol 2008;52:410-412.

18. Iliev ME, Domig D, Wolf-Schnurrbursch $U$, et al. Intravitreal bevacizumab (Avastin) in the treatment of neovascular glaucoma. Am $\mathrm{J}$ Ophthalmol 2006;142:1054-1056.

19. Fung AE, Rosenfeld PJ, Reichel E. The International Intravitreal Bevacizumab Safety Survey: using the internet to assess drug safety worldwide. Br J Ophthalmol 2006;90:1344-1349.

20. Mason JO 3rd, White MF, Feist RM, et al. Incidence of acute onset endophthalmitis following intravitreal bevacizumab (Avastin) injection. Retina 2008;28:564-567.

21. Fintak DR, Shah GK, Blinder KJ, et al. Incidence of endophthalmitis related to intravitreal injection of bevacizumab and ranibizumab. Retina 2008;28:1395-1399.

22. Pilli S, Kotsolis A, Spaide RF, et al. Endophthalmitis associated with 
intravitreal anti-vascular endothelial growth factor therapy injections in an office setting. Am J Ophthalmol 2008;145:879-882.

23. Jonas JB, Spandau UH, Schlichtenbrede F. Short-term complications of intravitreal injections of triamcinolone and bevacizumab. Eye 2008;22:590-591.

24. Jonas JB, Spandau UH, Rensch F, et al. Infectious and noninfectious endophthalmitis after intravitreal bevacizumab. J Ocul Pharmacol Ther 2007;23:240-242.

25. Pieramici DJ, Avery RL, Castellarin AA, et al. Case of anterior uveitis after intravitreal injection of bevacizumab. Retina 2006;26:841-842.

26. Bakri SJ, Larson TA, Edwards AO. Intraocular inflammation following intravitreal injection of bevacizumab. Graefes Arch Clin Exp Ophthalmol 2008;246:779-781.

27. Yenerel NM, Dinc UA, Gorgun E. A case of sterile endophthalmitis after repeated intravitreal bevacizumab injection. $\mathrm{J}$ Ocul Pharmacol Ther 2008;24:362-363.

28. Taban M, Singh RP, Chung JY, et al. Sterile endophthalmitis after intravitreal triamcinolone: a possible association with uveitis. Am J Ophthalmol 2007; $144: 50-54$

29. Roth DB, Chieh J, Spirn MJ, et al. Noninfectious endophthalmitis associated with intravitreal triamcinolone injection. Arch Ophthalmol $2003 ; 121: 1279-1282$.

30. Stepien KE, Eaton AM, Jaffe GJ, et al. Increased incidence of sterile 
endophthalmitis after intravitreal triamcinolone acetonide in Spring 2006. Retina 2009;29:207-213.

31. Wickremasinghe SS, Michalova K, Gilhotra J, et al. Acute intraocular inflammation after intravitreous injections of bevacizumab for treatment of neovascular age-related macular degeneration. Ophthalmology 2008;115:1911-1915. 
Figure Legend

Visual acuity in logMAR immediately before intravitreal injection of bevacizumab (x-axis) and at the final examination one month after the injection (y-axis). Circles indicate eyes without ocular inflammation; triangles indicate eyes with moderate inflammation; reversed triangles indicate eyes with ocular inflammation severe enough to require pars plana vitrectomy. 


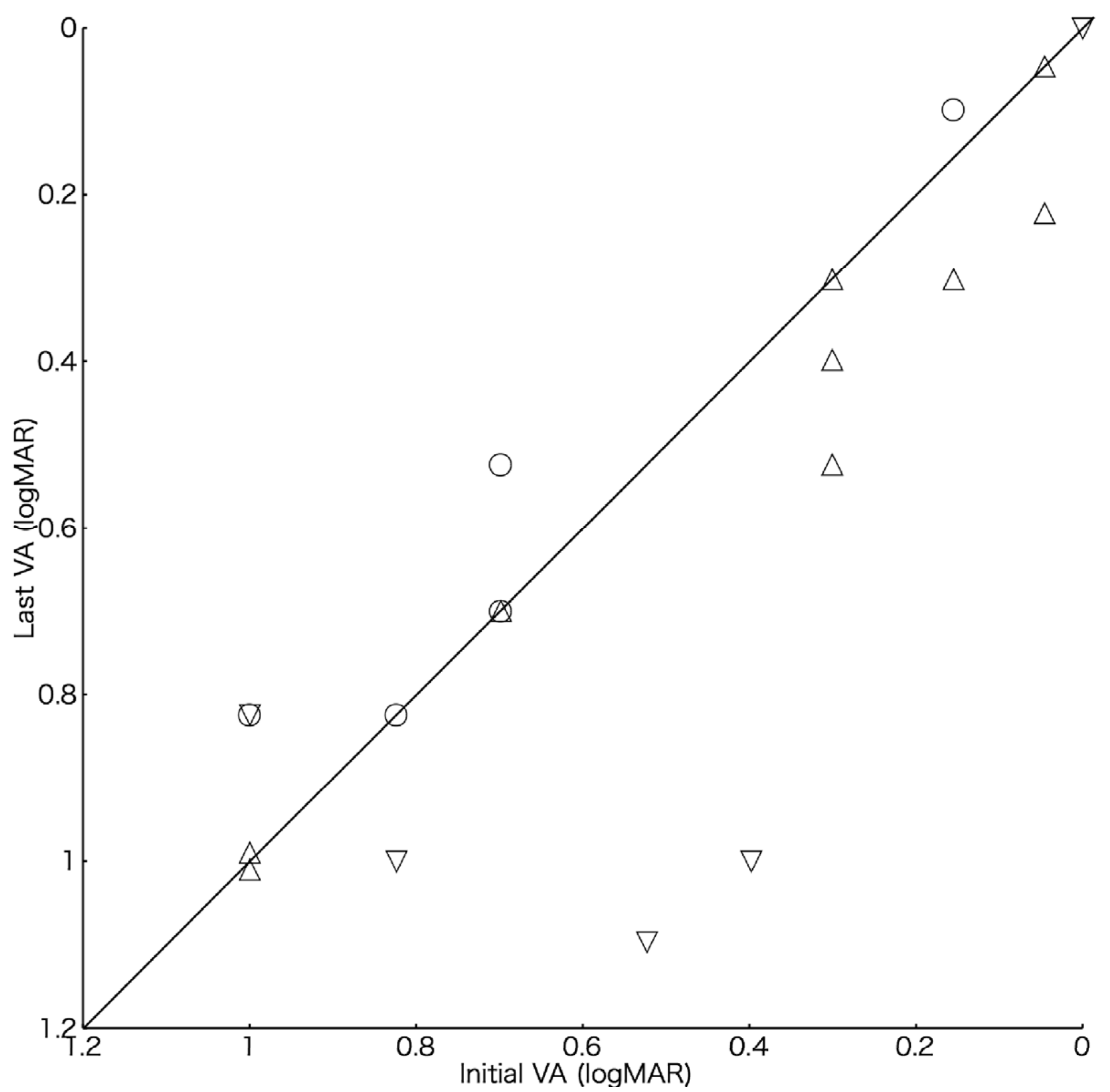


Table 1. Patient Demographics

\begin{tabular}{|c|c|c|c|c|c|c|c|c|c|}
\hline No. & Age & $R / L$ & Disease & $\begin{array}{l}\text { IVB } \\
\text { With: }\end{array}$ & $\begin{array}{l}\text { Prior } \\
\text { IVB }\end{array}$ & $\begin{array}{l}\text { Lens } \\
\text { Status }\end{array}$ & $\begin{array}{l}\text { Pre } \\
\text { VA }\end{array}$ & $\begin{array}{l}\text { Final } \\
\text { VA }\end{array}$ & $\begin{array}{l}\text { Ocular } \\
\text { Inflammation }\end{array}$ \\
\hline 1 & 89 & L & PCV & $\begin{array}{l}\text { IVTA } \\
\text { PDT }\end{array}$ & 0 & Cataract & 0.70 & 0.52 & None \\
\hline 2 & 81 & $L$ & RAP & & 1 & Cataract & 0.70 & 0.70 & None \\
\hline 3 & 79 & L & BRVO & & 1 & PC-IOL & 0.16 & 0.10 & None \\
\hline 4 & 59 & $L$ & AMD & PDT & 0 & Cataract & 0.82 & 0.82 & None \\
\hline \multirow{2}{*}{5} & \multirow{2}{*}{77} & $\mathrm{R}$ & AMD & & 2 & Cataract & 1.00 & 0.82 & None \\
\hline & & L & AMD & & 2 & Cataract & 0.30 & 0.52 & Moderate \\
\hline 6 & 77 & $\mathrm{R}$ & BRVO & & 2 & Cataract & 1.00 & 1.00 & Moderate \\
\hline 7 & 80 & $\mathrm{R}$ & AMD & $\begin{array}{l}\text { IVTA } \\
\text { PDT }\end{array}$ & 0 & Cataract & 0.70 & 0.70 & Moderate \\
\hline 8 & 68 & $\mathrm{R}$ & BRVO & & 0 & Aphakia & 0.30 & 0.30 & Moderate \\
\hline 9 & 82 & $\mathrm{~L}$ & AMD & & 4 & Cataract & 0.30 & 0.40 & Moderate \\
\hline 10 & 91 & $\mathrm{R}$ & AMD & & 0 & PC-IOL & 0.16 & 0.30 & Moderate \\
\hline 11 & 72 & $\mathrm{R}$ & PCV & & 5 & Cataract & 0.05 & 0.22 & Moderate \\
\hline \multirow{2}{*}{12} & \multirow{2}{*}{78} & $\mathrm{R}$ & AS & & 2 & PC-IOL & 1.00 & 1.00 & Moderate \\
\hline & & $L$ & AS & & 0 & Cataract & 0.05 & 0.05 & Moderate \\
\hline \multirow{2}{*}{13} & \multirow{2}{*}{84} & $\mathrm{R}$ & RAP & & 5 & PC-IOL & 0.00 & 0.00 & Severe \\
\hline & & L & RAP & & 0 & PC-IOL & 1.00 & 0.82 & Severe \\
\hline 14 & 61 & L & $\mathrm{mCNV}$ & & 1 & Cataract & 0.52 & 1.10 & Severe \\
\hline \multirow{2}{*}{15} & \multirow{2}{*}{82} & $\mathrm{R}$ & $\mathrm{mCNV}$ & & 1 & PC-IOL & 0.40 & 1.00 & Severe \\
\hline & & L & $\mathrm{mCNV}$ & & 4 & PC-IOL & 0.82 & 1.00 & Severe \\
\hline
\end{tabular}

PCV, polypoidal choroidal vasculopathy; RAP, retinal angiomatous proliferation; BRVO, branch retinal vein occlusion; AMD, age-related macular degeneration; AS, angioid streaks; mCNV, myopic choroidal neovascularization; IVB, intravitreal injection of bevacizumab; IVTA, intravitreal injection of triamcinolone acetonide simultaneously with IVB; PDT, photodynamic therapy three days after IVB; PC-IOL, posterior chamber intraocular lens; Pre VA, visual acuity immediately before IVB; Final VA, visual acuity at one month after IVB. 
Table 2. Clinical Findings of Sterile Endophthalmitis after Intravitreal Injection of Bevacizumab

\begin{tabular}{|c|c|c|c|c|c|c|c|c|c|}
\hline No. & $\mathrm{R} / \mathrm{L}$ & $\begin{array}{l}\text { Time to } \\
\text { Presentation }\end{array}$ & Pain & $\begin{array}{l}\text { Conjunctival } \\
\text { Hyperemia }\end{array}$ & Hypopyon & $\begin{array}{l}\text { AC } \\
\text { Cells }\end{array}$ & $\begin{array}{l}\text { Vit. } \\
\text { Opacity }\end{array}$ & Treatment & Culture \\
\hline 5 & $\mathrm{~L}$ & 3 days & & & & + & + & Steroid and antibiotics (topical) & \\
\hline 6 & $\mathrm{R}$ & 2 days & & + & & + & & Steroid and antibiotics (topical) & \\
\hline 7 & $\mathrm{R}$ & 2 days & & & & + & + & Antibiotics (topical) & \\
\hline 8 & $\mathrm{R}$ & 2 days & & ++ & & ++ & & Steroid and antibiotics (topical) & \\
\hline 9 & L & 1 day & & & & & + & Steroid and antibiotics (topical) & \\
\hline 10 & $\mathrm{R}$ & 7 days & & & & & + & Antibiotics (topical) & \\
\hline 11 & $\mathrm{R}$ & 1 day & + & + & & + & ++ & Steroid and antibiotics (topical and systemic) & \\
\hline \multirow{2}{*}{12} & $\mathrm{R}$ & 3 days & & & & ++ & ++ & Steroid and antibiotics (topical and systemic) & \\
\hline & L & 3 days & & & & ++ & ++ & Steroid and antibiotics (topical and systemic) & \\
\hline \multirow{2}{*}{13} & $\mathrm{R}$ & 1 day & + & ++ & + & ++ & +++ & PPV & Negative \\
\hline & L & 1 day & + & ++ & + & ++ & +++ & PPV & Negative \\
\hline 14 & $\mathrm{~L}$ & 2 days & + & ++ & + & ++ & +++ & PPV & Negative \\
\hline \multirow{2}{*}{15} & $\mathrm{R}$ & 1 day & + & ++ & & +++ & +++ & PPV & Negative \\
\hline & L & 1 day & + & ++ & & +++ & +++ & PPV & Negative \\
\hline
\end{tabular}

AC cells, cellular infiltration into anterior chamber; Vit. Opacity, vitreous opacity; PPV, pars plana vitrectomy. Anterior chamber cells were graded as follows; (+), 5-20 cells, (++), 20-50cells, and (+++) more than 50 cells per $1 \times 1 \mathrm{~mm}$ slitbeam field. Vitreous opacity was graded as follows; (+), retinal vessels are hazily visible, $(++)$, optic nerve head is visible but border of the optic nerve head is quite blurry, and $(+++)$, optic nerve head is obscure. 